\title{
Survivin expression, HPV positivity and microvessel density in oropharyngeal carcinomas and relationship with survival time
}

Ebru Tastekin ${ }^{1}$, Vuslat Yurut Caloglu², Nilufer Kilic Durankus², Necdet Sut ${ }^{3}$, Gorkem Turkkan², Nuray Can ${ }^{1}$, Fulya Oz Puyan ${ }^{1}$, Murat Caloglu²

${ }^{1}$ Department of Pathology, Medical Faculty, Trakya University, Edirne, Turkey ${ }^{2}$ Department of Radiation Oncology, Faculty of Medicine, Trakya University, Edirne, Turkey ${ }^{3}$ Department of Biostatistics, Faculty of Medicine, Trakya University, Edirne, Turkey

Submitted: 17 July 2015

Accepted: 11 October 2015

Arch Med Sci 2017; 13, 6: 1467-1473

DOI: 10.5114/aoms.2015.56616

Copyright (C) 2016 Termedia \& Banach

\section{Abstract}

Introduction: Among head and neck cancers, those of the oral cavity and oropharynx are the second most prevalent following the larynx. This study aimed to research immunohistochemical expression of survivin, HPV positivity and microvessel density in tumors and their relationships with prognosis. Material and methods: Pathological materials and demographic properties of 46 patients were retrospectively evaluated. Survivin, HPV and CD34 (for microvessel density evaluation) antibodies were applied tumoral tissues. Survival times, clinical stage and differentiation were evaluated.

Results: In univariate analysis, we observed that survivin, microvessel density and stage were significantly associated with survival time $(p<0.05)$. In multivariate analysis, only survivin and microvessel density were associated with survival time $(p<0.05)$. But we did not find significant correlation between neither tumor differentiation nor HPV positivity and survival $(p>0.05)$.

Conclusions: Survivin levels and microvessel density were found to be effective prognostic factors and were related to survival in oral cavity and oropharyngeal cancers. Treatments targeting survivin expression and angiogenesis might be employed against these tumor groups.

Key words: oral cavity tumors, oropharyngeal carcinoma, prognosis, survivin.

\section{Introduction}

Oral cavity and oropharyngeal cancers, known as oral carcinomas, are actually heterogeneous diseases with various behaviors. Ninety percent of these diseases are squamous cell carcinomas (SCC) [1]. Oral SCC are the $6^{\text {th }}$ most commonly observed malignancy in the world [2]. Oral cavity carcinomas arise from the tongue, palate, cheek, retromolar triangle and gingiva [3]. Such cancer types are more prevalent among men, yet rising tobacco and alcohol consumption has caused an increasing rate of prognosis among women [3]. These tumors are known as rapidly progressive, and distant metastases have been reported in 53\% of them [4]. Even though early diagnosis and treatment methods have advanced, the 5 -year survival rate is $50-55 \%[5,6]$.

\author{
Corresponding author: \\ Ebru Tastekin \\ Department of Pathology \\ Medical Faculty \\ Trakya University \\ 22030 Edirne, Turkey \\ Phone: +90 2842357642-1532 \\ E-mail: ebrutastekin@ \\ hotmail.com
}


Radiotherapy along with surgical treatments is equally successful in early cases of oral cavity carcinomas. Tumors that are at advanced stages require surgical and postoperative radiotherapy. Chemotherapy is also used in these cases [3].

Survivin is a member of the inhibitor of apoptosis (IAP) family. Survivin is not found in normal human tissue, but it is expressed in many cancer types. These properties make survivin a prime molecular target for cancer treatment [7-11]. There are numerous reports about survivin expression and its correlation with poor prognosis and drug resistance [12]. Recent studies have shown that survivin expression has a direct correlation with survival in SCC $[13,14]$.

Apart from playing a role in progression of cervical cancer in women, human papilloma virus (HPV) has a correlation with carcinogenesis of oral carcinomas [15]. Oral HPV infection is related to sexual behavior [16]. In oral carcinomas, HPV 16 prevalence was determined as $22 \%$ and HPV 18 as 14\% [17]. HPV plays a significant role (up to $45 \%$ ) in the etiology of SCC in oropharyngeal, lingual and palatine tonsil carcinomas [18, 19]. Tongue carcinomas have a HPV prevalence of $25 \%$ [20]. According to some studies, HPV status of tumors has a relation with response to treatment and survival rates, HPV positivity having better results in oropharyngeal carcinomas [21].

Both primary and metastatic tumors need nutrients and oxygen. Angiogenesis (neovascularization) is necessary in order to obtain oxygen and nutrition [22]. Until tumors reach 2-3 $\mathrm{mm}$ in size, tumors can obtain their necessities by diffusion. Afterwards endothelial cells migrate to the stroma by means of angiogenesis stimulation [23]. Angiogenic factors were expressed by tumor cells continuously or as responses to external stimulations. Hypoxia, lymphocytes infiltrating tumor, materials secreted by macrophages and mast cells can lead to angiogenesis $[24,25]$. Other factors that can lead to an angiogenic response at a micro level include cytokines and growth factors. All of these factors increase the vascular endothelial growth factor (VEGF) expression [26].

Tumor angiogenesis leads to increased tumor cell circulation and also increases the possibility of metastasis. In most tumor types, it is observed that a small vein count in the microscopic range leads to an increase in metastasis and decrease in survival rate. Tumor angiogenesis is an important step in tumor growth and metastasis [27]. The numerical count of tumor angiogenesis is described as microvessel density (MVD). Antibodies such as CD31, CD34, CD105 and von Willebrand factor (factor VIII), which are specific to vein endothelium, are used for MVD evaluation. Recent studies have shown that MVD is correlated with advanced stage and poor prognosis in tumors of the breast, lung colon, stomach, skin, prostate and kidney [28, 29].

Angiogenesis, survivin expression and HPV positivity are important factors used for predicting prognosis in oropharyngeal carcinomas. This study aims to identify the prognostic importance of angiogenesis, survivin and HPV positivity in patients treated with curative radiotherapy and chemotherapy.

\section{Material and methods}

\section{Patients' selection}

Data and demographic properties of 46 patients who had undergone mucosal biopsy diagnosed as squamous cell carcinoma in the pathology department were included in the study. All of the patients were treated with the radiotherapy-chemotherapy regimen as described below and were evaluated retrospectively. Patients under the age of 18 and those diagnosed with malignancy other than SCC were excluded.

\section{Pathological method}

Tumor staging was assessed according to the 2010 American Joint Committee on Cancer staging criteria [30]. Histological grading was performed in a blind manner following the World Health Organization criteria for squamous cell carcinomas of the oral mucosa.

Survivin antibody (polyclonal rabbit, Clone N/A, 1 : 100, Novus Biologicals, Littleton, USA), HPV antibody (cocktail broad spectrum, Clone BPV-1/IH8+CAMVIR-1, 1/80 dilution, Biocare Medical, Concord, USA) and CD34 antibody (polyclonal rabbit, Clone QBEND-10, 1/200, Thermo Scientific, Waltham, Massachusetts, USA) were applied to the 5-micron thick slides obtained from paraffin blocks containing tumoral area. Control tissues were stained colon adenocarcinoma for survivin, infected cervical tissue for HPV and normal kidney tissue for CD34. Sections were deparaffinized by passing through xylene, and rehydrated by a graded series of ethanol. After antigen retrieval by heating in citrate buffer at $60^{\circ} \mathrm{C}$ in an incubator overnight, the sections were treated with $3 \% \mathrm{H}_{2} \mathrm{O}_{2}$ in methanol for 20 min to abolish endogenous peroxidase activity. Then the sections were incubated with CD34 and HPV antibodies for $25 \mathrm{~min}$. Sections were incubated with $2 \mu \mathrm{g} / \mathrm{ml}$ anti-survivin at $48^{\circ} \mathrm{C}$ overnight. Respectively, anti-polyvalent biotinylated antibody, PBS, anti-polyvalent biotinylated antibody, PBS, AEC substrate and hematoxylin-eosin steps were applied.

Nuclear and cytoplasmic staining of survivin antibody was evaluated. Cases with more than 5\% staining in tumors were rated as positive and were graded for staining prevalence in 3 categories: score 0: $<5 \%$; score 1: $5 \%$ to $25 \%$; score 2: $26 \%$ to $50 \%$; score 3: $51 \%$ to $75 \%$; score 4 : > $75 \%$ [13]. 
CD34 antibody was used for assessing microvessel density. Tissues were scanned for the optimum staining point, and then micro veins in the stroma of outlying tumor islands in $10 \mathrm{HPF}$ areas were counted and equated [31].

Tumor cells were rated as positive in nuclear staining for HPV antibodies [32].

\section{Radiotherapy}

Patients with locally advanced disease were treated using parallel opposed lateral fields until 2004. After 2004, patients were treated using 3D conformal radiotherapy techniques. 70 Gy of radiotherapy was given to the primary tumor and clinically involved nodes, while 50-60 Gy of radiotherapy was given for subclinical disease.

\section{Chemotherapy}

All patients were simultaneously given $100 \mathrm{mg} /$ $\mathrm{m}^{2}$ of cisplatin for 21-day intervals.

\section{Statistical analysis}

Demographic-clinical characteristic of patients are shown as mean \pm standard deviation or number (percentage). Survival times by clinical stage and differentiation were analyzed using Kaplan-Meier survival analysis, then the log-rank test was used for group comparisons. Relationships of survivin and CD34 with clinical stage and differentiation were analyzed using Spearman correlation analysis. Comparisons of survivin and CD-34 level by clinical stage were analyzed by the Mann-Whitney $U$ test and Student's $t$ test, respectively. Comparisons of survivin and CD-34 level by differentiation were analyzed by the Kruskal-Wallis test and one-way ANOVA test, respectively. Independent effects of demographic-clinical characteristics (age, gender, survivin, CD34, clinical stage and differentiation) on survival were analyzed by a univariate Cox regression model, then we analyzed all likely prognostic factors by multivariate backwards stepwise Cox regression analysis. A $p$-value $<0.05$ was considered statistically significant. Statistical analysis was performed using SPSS 20.0 (IBM Corp. Released
2011. IBM SPSS Statistics for Windows, Version 20.0. Armonk, NY: IBM Corp.).

\section{Results}

The average age was $59.48 \pm 11.43$ ( $\min : 31$, max: 91$)$. Ten (21.74\%) patients were female and $36(88.26 \%)$ were male. Average survival time was $30.94 \pm 25.24$ months.

Clinically, 12 patients (26\%) had stage I-II and 34 (74\%) patients had stage III-IV disease. We observed a statistically significant correlation between tumor clinical stage and survival $(p<0.006)$ (Table I).

Twenty-six (56.5\%) patients had poorly differentiated tumors. Seven (15.2\%) patients had moderately differentiated tumors and 13 (28.3\%) patients had well-differentiated tumors (Figure 1). We did not observe a statistically significant correlation between differentiation and survival rate $(p=0.423)$ (Table I).

Survivin scores were $0,1,2,3,4$ respectively in 1 (2.2\%), 6 (13.0\%), 6 (13.0\%), 14 (30.4\%), and 19 (41.3\%) patients. We detected a significant correlation between survivin positivity and survival rate $(p<0.05)$ (Figure 2 ).

A positive reaction with HPV antibody was seen in 3 of the patients. We observed no relationship between HPV status and survival rate $(p>0.05)$.

Microvessel density mean value was 41.26 \pm 16.13 (min: 12 , max: 75 ). We found a significant correlation between MVD count and survival rate $(p<0.05)$.

Effects of some demographic and clinical characteristics on survival rate are shown in Table II. Among the variables (survivin, CD34, and clinical stage) that were entered in the backward stepwise Cox regression model, survivin and CD34 were found to be significant prognostic factors for survival. According to this model, survivin positivity increased the mortality risk 3.176-fold (95\% Cl: 1.539-6.554) and MVD count increased the mortality risk 1.075 -fold (95\% Cl: $1.030-1.123)$ in patients with oropharyngeal carcinoma.

Survivin scores and CD-34 levels were higher in patients with clinical stages III-IV (respectively,

Table I. Clinical characteristic and average survival time of patients

\begin{tabular}{|lcccc|}
\hline Parameter & & $\boldsymbol{N}(\%)$ & $\begin{array}{c}\text { Survival [months] } \\
\text { Mean } \pm \text { SD }\end{array}$ & -value \\
\hline Clinical stage & I-II & $12(26.09)$ & $85.97 \pm 17.33$ & 0.027 \\
\cline { 2 - 4 } & III-IV & $34(73.91)$ & $32.41 \pm 6.19$ & \multirow{2}{*}{0.423} \\
\cline { 2 - 4 } Differentiation & Good & $13(28.26)$ & $40.99 \pm 7.45$ & \\
\cline { 2 - 4 } & Moderate & $7(15.22)$ & $23.29 \pm 5.37$ & $66.69 \pm 17.08$ \\
\cline { 2 - 4 } & Poor & $26(56.52)$ & & \\
\hline
\end{tabular}



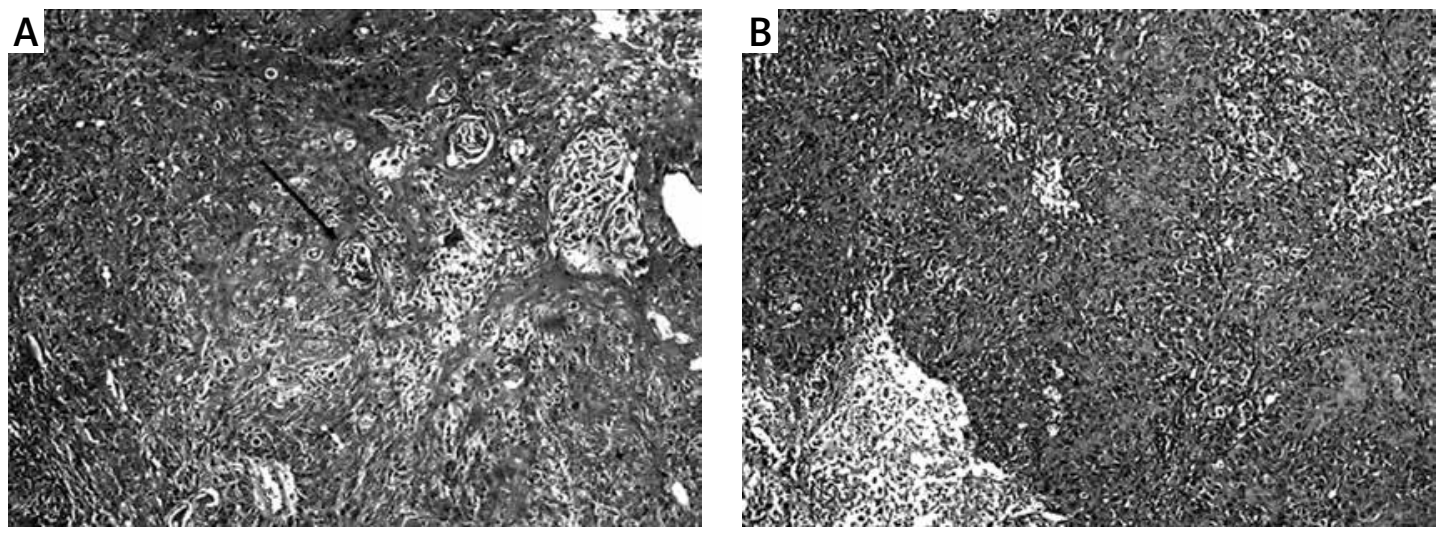

Figure 1. Microscopic features of oropharyngeal squamous cell carcinoma. A - Well-differentiated type (arrow: keratin pearl), B - Poorly differentiated type, H + E 50x
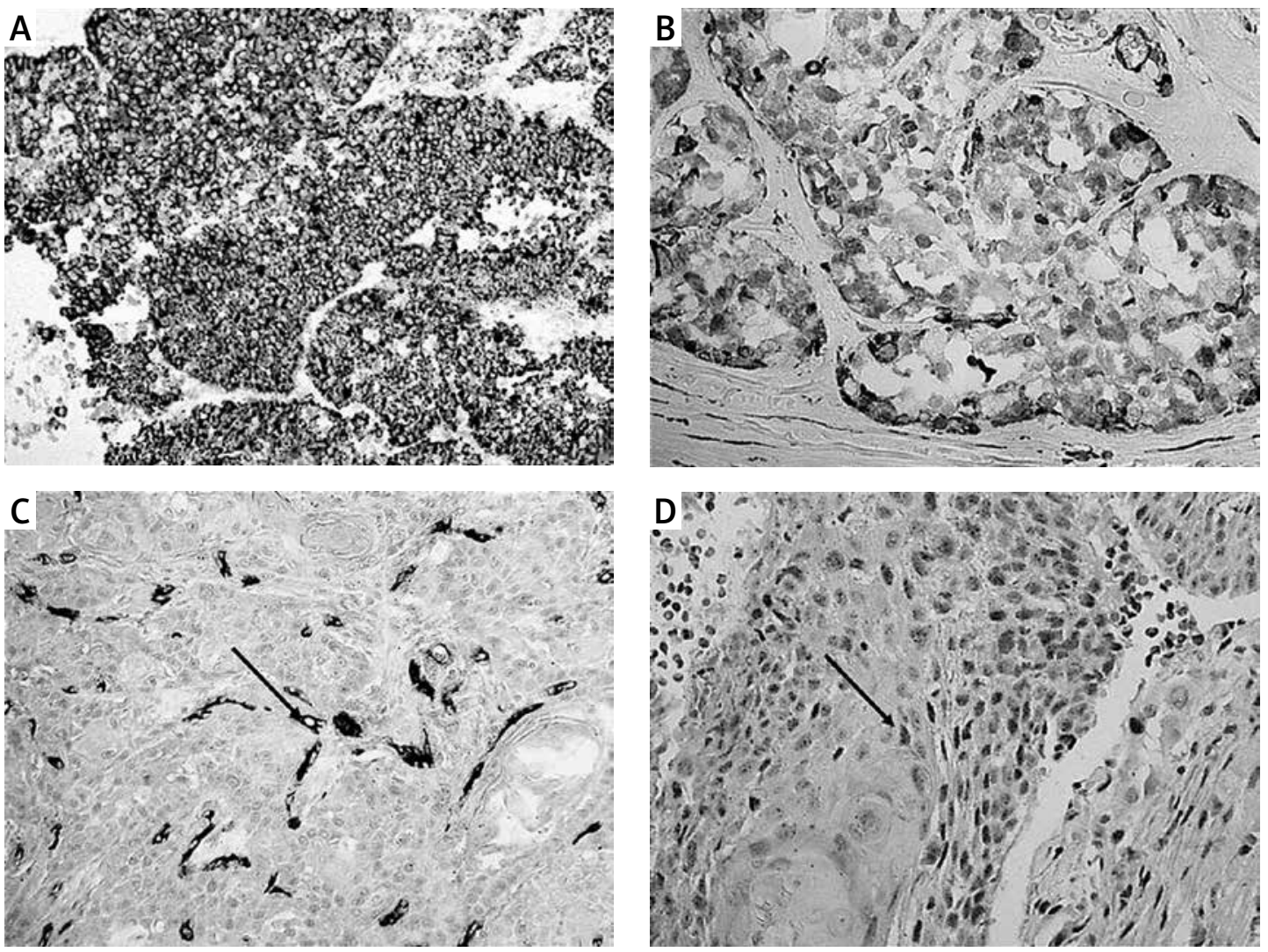

Figure 2. Immunoperoxidase staining examples. A - Diffuse strongly survivin antibody positivity, 50x, B - Focally moderate survivin positivity, 100×, C - Microvessel density evaluation with CD34 antibody (arrow: a stained vessel) 50x, D - HPV positivity in tumoral cells (arrow: a nuclear positivity), 100x

$p<0.001 ; p=0.002)$. In addition, survivin scores and CD-34 levels were significantly higher in patients with moderate differentiation than good differentiation (respectively $p=0.045 ; 0.041$ ) (Table III). Survivin scores and CD-34 levels were significantly correlated with clinical stage $(p<0.001$, Table IV).

\section{Discussion}

Recent studies about some carcinoma types are usually geared towards prognosis, prediction of survival, treatment resistance and also target-based treatments [33, 34]. Some studies about oropharyngeal carcinoma are focused on this issue. Recently, a significant correlation was detected between survivin positivity, which is an inhibitor of apoptosis, and carcinogenesis [7]. In our study, we observed a direct correlation between survivin levels in oropharyngeal tumors and survival rate, which may help in planning of new medication research about inhibition of the survivin pathway. In our study, as well as parameters such as tumor differentiation and stage, which are known have an effect on prognosis, we 
Table II. Effect of demographic-clinical characteristics on survival

\begin{tabular}{|c|c|c|c|c|c|c|}
\hline \multirow[t]{2}{*}{ Parameter } & \multicolumn{3}{|c|}{ Univariate } & \multicolumn{3}{|c|}{ Multivariate* $^{\star}$} \\
\hline & OR & $95 \% \mathrm{Cl}$ for $\mathrm{OR}$ & $P$-value & OR & $95 \% \mathrm{Cl}$ for $\mathrm{OR}$ & $P$-value \\
\hline Age & 0.978 & $0.944-1.013$ & 0.211 & - & - & - \\
\hline Gender, female & 1.669 & $0.662-4.208$ & 0.277 & - & - & - \\
\hline Survivin & 4.922 & $2.578-9.399$ & $<0.001$ & 3.176 & $1.539-6.554$ & 0.002 \\
\hline CD34 & 1.119 & $1.074-1.166$ & $<0.001$ & 1.075 & $1.030-1.123$ & 0.001 \\
\hline Stage, III-IV & 3.804 & $1.364-10.606$ & 0.011 & - & - & - \\
\hline Differentiation: & & & 0.280 & - & - & - \\
\hline Poor & 1 & Reference & 0.440 & - & - & - \\
\hline Moderate & 1.408 & $0.463-4.281$ & 0.547 & - & - & - \\
\hline Good & 0.635 & $0.255-1.582$ & 0.330 & - & - & - \\
\hline
\end{tabular}

${ }^{\star}$ Backward stepwise Cox regression analysis.

Table III. Comparisons of survival time, survivin and CD-34 level by clinical characteristics

\begin{tabular}{|c|c|c|c|c|c|c|c|}
\hline \multirow[t]{2}{*}{ Parameter } & \multicolumn{2}{|c|}{ Clinical stage } & \multirow[t]{2}{*}{$P$-value } & \multicolumn{3}{|c|}{ Differentiation } & \multirow[t]{2}{*}{$P$-value } \\
\hline & $\begin{array}{c}\mathrm{I}-\mathrm{II} \\
(n=12)\end{array}$ & $\begin{array}{c}\text { III-IV } \\
(n=34)\end{array}$ & & $\begin{array}{c}\text { Good } \\
(n=13)\end{array}$ & $\begin{array}{c}\text { Moderate } \\
(n=7)\end{array}$ & $\begin{array}{c}\text { Poor } \\
(n=26)\end{array}$ & \\
\hline Survivin & $1.5(0-3)$ & $4(1-4)$ & $<0.001$ & $2(0-4)$ & $4(2-4)$ & $3(1-4)$ & 0.045 \\
\hline CD-34 level & $29.4 \pm 10.9$ & $45.4 \pm 15.6$ & 0.002 & $36.0 \pm 16.1$ & $54.5 \pm 14.9$ & $40.2 \pm 15.0$ & 0.041 \\
\hline
\end{tabular}

Mean \pm standard deviation; median (minimum - maximum).

studied the effects of survivin, HPV positivity and MVD on survival and demonstrated that all factors that are listed apart from HPV positivity are associated with prognosis.

Survivin is a protein that inhibits apoptosis (a member of inhibitor of apoptosis proteins the IAP family). It is thought that survivin protein promotes tumor growth and progression by inhibiting apoptosis and increasing cell proliferation [35]. The role of abnormal expression of survivin protein in increased cell proliferation due to molecular carcinogenesis and apoptosis is well documented. Likewise, there are various published studies indicating that survivin is a negative prognostic factor regarding survival. Recent studies have noted that bladder, colon, rectum, lung, stomach and breast cancers all have abnormal expression of the survivin gene [36, 37]. Consistent with all these findings, we observed a significant relationship between survivin staining levels and survival rates. However, Zhang et al. [38] observed no relation between survivin staining level and survival rates, in contrast with our study. In this study, the univariate analysis demonstrated a 4.9fold and the multivariate analysis demonstrated a 3.2-fold positive effect of the survivin staining score on survival rate. These results show the direct relation between the survival rate and survivin staining score in the patients.
Table IV. Correlations between survivin and CD-34 level with clinical characteristics

\begin{tabular}{|lcc|}
\hline Variable & Clinical stage & Differentiation \\
\hline Survivin & $r=0.768^{\dagger}$ & $r=-0.211^{\mathrm{NS}}$ \\
\hline CD-34 level & $r=0.524^{\dagger}$ & $r=-0.036^{\mathrm{NS}}$ \\
\hline
\end{tabular}

${ }^{\dagger} p<0.001, N S-$ non-significant.

Angiogenesis, which means formation of new blood vessels, is critical for embryonic progress, normal growth and repair of damaged tissue. At the same time, it can be pathological. Especially, substances secreted by cancerous cells are stimulate to the angiogenesis. For this reason, cancer patients are prescribed anti-angiogenic chemotherapy agents as part of their treatment. Microvessel density is typically assessed feature in studies for angiogenic research and CD34 antibody is a credible marker for MVD evaluation. Recent studies have noted a direct correlation between MVD and poor course of disease in breast, lung, colon, stomach, malign melanoma, prostate and bladder cancer along with advanced pathological stage [39-41]. Kyzas et al. [42] studied microvessel density in 69 patients diagnosed with head and neck cancers. The patient population included oral cavity, larynx and lower lip cancer patients. De Oliveira et al. [43] observed that patients with locoregional metastases had a higher 
than average MVD. Another outcome of this study is that the microvascular density has an effect on the survival rate. A slight increase in the microvascular density may reveal a negative effect on survival rate.

Yu et al. [44] evaluated 1279 head and neck cancer patients' results in a meta-analysis containing data from 18 studies. In their study, mortality rate was determined as 1.23 times more in tumors with high microvessel density, but the difference was not statistically significant. But in our study, we observed a significant correlation between MVD and survival times.

Numerous studies have documented the effect of human papilloma virus on etiology of oropharyngeal carcinomas. Especially, there are many publications about HPV-16's correlation with base of tongue and oropharyngeal cancers [45, 46]. HPV stimulates the p16 INK4a pathway, and many studies have observed a better survival rate among patients who are HPV positive. Kanyilmaz et al. [47] reported that tumor positivity for p16 INK4a was correlated with improved disease-free survival and overall survival. However, we did not observe a correlation between HPV positivity and survival. This might be a result of the small number of HPV-positive cases in our study.

In our study, survivin levels and MVD were determined as effective prognostic factors and related to survival in oropharyngeal cancers. New treatment methods might be discovered in light of the relationship of survivin levels which is an inhibitor of apoptosis and is a significant factor in carcinogenesis with survival rates. An agent leading to blockage of survivin expression might be used as an alternative objective-oriented medication for oropharyngeal carcinomas.

The significant correlation between MVD in oropharyngeal carcinomas and survival leads us to believe that objective-oriented treatment agents targeting angiogenesis stages might be effective against this tumor group.

In conclusion, survivin levels and angiogenesis were determined as effective prognostic factors and were related to survival in oral cavity and oropharyngeal cancers. Treatments targeting survivin expression and angiogenesis might be employed against these tumor groups.

\section{Conflict of interest}

The authors declare no conflict of interest.

\section{References}

1. Wingo PA, Bolden S, Tong T, Parker SL, Martin LM, Heath CW Jr. Cancer statistics for African Americans, 1996. CA Cancer J Clin 1996; 46: 113-25.

2. Nagpal JK, Das BR. Oral cancer: reviewing the present understanding of its molecular mechanism and explor- ing the future directions for its effective management. Oral Oncol 2003; 39: 213-21.

3. Neville BW, Day TA. Oral cancer and precancerous lesions. CA Cancer J Clin 2002; 52: 195-215.

4. Wingo PA, Tong T, Bolden S. Cancer statistics, 1995. CA Cancer J Clin 1995; 45: 8-30.

5. Miller CS, Johnstone BM. Human papillomavirus as a risk factor for oral squamous cell carcinoma: a metaanalysis, 1982-1997. Oral Surg Oral Med Oral Pathol Oral Radiol Endod 2001; 91: 622-35.

6. Shiu MN, Chen TH, Chang SH, Hahn LJ. Risk factors for leukoplakia and malignant transformation to oral carcinoma: a leukoplakia cohort in Taiwan. Br J Cancer 2000; 82: 1871-4.

7. Altieri DC. Survivin, versatile modulation of cell division and apoptosis in cancer. Oncogene 2003; 22: 8581-9.

8. Altieri DC. Survivin in apoptosis control and cell cycle regulation in cancer. Prog Cell Cycle Res 2003; 5: 447-52.

9. Li F. Survivin study: what is the next wave? J Cell Physiol 2003; 197: 8-29.

10. Li F, Ling X. Survivin study: an update of "what is the next wave"? J Cell Physiol 2006; 208: 476-86.

11. Mesri M, Wall NR, Li J, Kim RW, Altieri DC. Cancer gene therapy using a survivin mutant adenovirus. J Clin Invest 2001; 108: 981-90.

12. Lo Muzio L, Farina A, Rubini C, et al. Survivin as prognostic factor in squamous cell carcinoma of the oral cavity. Cancer Lett 2005; 225: 27-33.

13. Chen PC, Kuo C, Pan CC, Chou MY. Risk of oral cancer associated with human papillomavirus infection, betel quid chewing, and cigarette smoking in Taiwan - an integrated molecular and epidemiological study of 58 cases. J Oral Pathol Med 2002; 31: 317-22.

14. Lin CY, Hung HC, Kuo RC, Chiang CP, Kuo MY. Survivin expression predicts poorer prognosis in patients with areca quid chewing-related oral squamous cell carcinoma in Taiwan. Oral Oncol 2005; 41: 645-54.

15. Rosenquist K, Wennerberg J, Schildt EB, Bladstrom A, Goran Hansson B, Andersson G. Oral status, oral infections and some lifestyle factors as risk factors for oral and oropharyngeal squamous cell carcinoma. A population-based case-control study in southern Sweden. Acta Otolaryngol 2005; 125: 1327-36.

16. Sugerman PB, Shillitoe EJ. The high risk human papillomaviruses and oral cancer: evidence for and against a causal relationship. Oral Dis 1997; 3: 130-47.

17. Singh M, Bleile MJ, Shroyer AL, Heinz D, Jarboe EA, Shroyer KR. Analysis of survivin expression in a spectrum of benign to malignant lesions of the breast. Appl Immunohistochem Mol Morphol 2004; 12: 296-304.

18. Asanuma H, Torigoe T, Kamiguchi K, et al. Survivin expression is regulated by coexpression of human epidermal growth factor receptor 2 and epidermal growth factor receptor via phosphatidylinositol 3-kinase/AKT signaling pathway in breast cancer cells. Cancer Res 2005; 65: 11018-25.

19. Hitt R, Echarri MJ. Molecular biology in head and neck cancer. Clin Transl Oncol 2006; 8: 776-9.

20. Mellin H, Dahlgren L, Munck-Wikland E, et al. Human papillomavirus type 16 is episomal and a high viral load may be correlated to better prognosis in tonsillar cancer. Int I Cancer 2002; 102: 152-8.

21. Folkman J. Role of angiogenesis in tumor growth and metastasis. Semin Oncol 2002; 29: 15-8.

22. Auerbach W, Auerbach R. Angiogenesis inhibition: a review. Pharmacol Ther 1994; 63: 265-311.

23. Biroccio A, Candiloro A, Mottolese $\mathrm{M}$, et al. Bcl-2 overexpression and hypoxia synergistically act to modulate 
vascular endothelial growth factor expression and in vivo angiogenesis in a breast carcinoma line. Faseb J 2000; 14: 652-60.

24. De Wever O, Mareel M. Role of tissue stroma in cancer cell invasion. J Pathol 2003; 200: 429-47.

25. Fidler IJ, Langley RR, Kerbel RS, Ellis LM. Biology of cancer: angiogenesis. In: Cancer: principles and practice of oncology. $7^{\text {th }}$ ed. De Vita VT Jr, Hellman S, Rosenberg SA (eds). Philadelphia, Lippincott Williams \& Wilkins 2005; 129-37.

26. Offersen BV, Pfeiffer P, Hamilton-Dutoit S, Overgaard J. Patterns of angiogenesis in nonsmall-cell lung carcinoma. Cancer 2001; 91: 1500-9.

27. Acar C, Sozen S, Erdem O, Gurocak S, Yılmaz G, Bozkırlı I. Relation between microvessel density, expression of ki-67 and p53 with clinicopathologic parameters and patient prognosis in prostate cancer. Urooncology 2006; 32: 478-85.

28. Burgesser MV, Riva V, Ojeda SM, Munoz Morales D, Calafat P, Diller A. Expression of VEGF-A, HIF-1 A, CD34 and Ki67 in clear cell renal cell carcinomas and their relationship with conventional prognostic markers. Rev Fac Cien Med Univ Nac Cordoba 2014; 71: 7-15.

29. Oken MM, Creech RH, Tormey DC, et al. Toxicity and response criteria of the Eastern-Cooperative-Oncology-Group. Am J Clin Oncol Cancer Clin Trials 1982; 5 649-55.

30. Frederick L. Pharynx (including base of tongue, Soft Palate, and Uvula). In: AJCC Cancer Staging Manual. Edge SB, Fritz AG, Byrd DR, Greene FL, Compton CC, Trotti A (eds.). $7^{\text {th }}$ ed. Springer, New York 2010; 41-56.

31. Marklund L, Hammarstedt L. Impact of HPV in oropharyngeal cancer. J Oncol 2011; 2011: 509036.

32. Atasoy BM, Dane F, Sarı M, et al. Cisplatin-based concomitant chemoradiotherapy in locally advanced squamous cell. Turk J Oncology 2008; 23: 1-11.

33. Wang Z, Hao B, Yang Y, et al. Prognostic role of SPARC expression in gastric cancer: a meta-analysis. Arch Med Sci 2014; 10: 863-9.

34. Zmijewska-Tomczak M, Milecki P, Olek-Hrab K, et al. Factors influencing quality of life in patients during radiotherapy for head and neck cancer. Arch Med Sci 2014; 10: 1153-9.

35. Jaiswal PK, Goel A, Mandhani A, Mittal RD. Functional polymorphisms in promoter survivin gene and its association with susceptibility to bladder cancer in North Indian cohort. Mol Biol Rep 2012; 39: 5615-21.

36. Wang YH, Chiou HY, Lin CT, et al. Association between survivin gene promoter-31 C/G polymorphism and urothelial carcinoma risk in Taiwanese population. Urology 2009; 73: 670-4.

37. Gazouli M, Tzanakis N, Rallis G, et al. Survivin $-31 \mathrm{G} / \mathrm{C}$ promoter polymorphism and sporadic colorectal cancer. Int J Colorectal Dis 2009; 24: 145-50.

38. Zhang $M$, Li J, Wang L, et al. Prognostic significance of p21, p27 and survivin protein expression in patients with oral squamous cell carcinoma. Oncol Lett 2013; 6: 381-6.

39. Ma J, Lu H, Wang S, et al. The anthraquinone derivative Emodin inhibits angiogenesis and metastasis through downregulating Runx2 activity in breast cancer. Int J Oncol 2015; 46: 1619-28.

40. Vassilakopoulou M, Psyrri A, Argiris A. Targeting angiogenesis in head and neck cancer. Oral Oncol 2015; 51 : 409-15.

41. Zhang X, Yamashita M, Uetsuki H, Kakehi Y. Angiogenesis in renal cell carcinoma: evaluation of microvessel density, vascular endothelial growth factor and matrix metalloproteinases. Int J Urol 2002; 9: 509-14.

42. Kyzas PA, Stefanou D, Batistatou A, Agnantis NJ. Prognostic significance of VEGF immunohistochemical expression and tumor angiogenesis in head and neck squamous cell carcinoma. J Cancer Res Clin Oncol 2005; 131: 624-30.

43. de Oliveira MV, Pereira Gomes EP, Pereira CS, et al. Prognostic value of microvessel density and p53 expression on the locoregional metastasis and survival of the patients with head and neck squamous cell carcinoma. Appl Immunohistochem Mol Morphol 2013; 21: 444-51.

44. Yu M, Liu L, Liang C, et al. Intratumoral vessel density as prognostic factors in head and neck squamous cell carcinoma: a meta-analysis of literature. Head Neck 2014; 36: 596-602.

45. Chaturvedi AK, Engels EA, Pfeiffer RM, et al. Human papillomavirus and rising oropharyngeal cancer incidence in the United States. J Clin Oncol 2011; 29: 4294-301.

46. Pintos J, Black MJ, Sadeghi N, et al. Human papillomavirus infection and oral cancer: a case-control study in Montreal, Canada. Oral Oncol 2008; 44: 242-50.

47. Kanyilmaz G, Ekinci O, Muge A, Celik S, Ozturk F. HPV-associated p16 INK4A expression and response to therapy and survival in selected head and neck cancers. Asian Pac J Cancer Prev 2015; 16: 253-8. 